\title{
BREVE REFLEXÃO SOBRE A REFORMA DO ENSINO MÉDIO E SUA RELAÇÃO COM A EDUCAÇÃO DE NIVEL SUPERIOR
}

Brief reflection on reform of middle school and its relationship with higher education

\author{
Helton Bernardino Lima ${ }^{1}$ \\ Francisca Emmanuella Saraiva Martins ${ }^{2}$ \\ Marcela Barroso Maciel $^{3}$
}

\begin{abstract}
RESUMO: Este estudo suscita uma breve reflexão sobre a reforma do ensino médio decretada em 2017 pelo presidente Michel Temer e sua relação com o ensino superior. Aprovada por meio de Medida Provisória (MP), esta reforma levantou uma série de controvérsias em virtude da escassez dos debates junto à sociedade a respeito das mudanças que a referida reforma produziria no currículo, tais como a permissão de o discente direcionar seus estudos de acordo com a área de maior interesse, e a possível aproximação com o mercado de trabalho. Além disso, a aplicabilidade desta reforma pelos Estados brasileiros ainda gera grande discussão, motivos estes que justificam a relevância da reflexão do presente estudo. Sendo assim, o objetivo do artigo é analisar sobre os efeitos que a reforma do ensino médio terá na formação, no acesso e na presença de alunos oriundos das escolas públicas no ensino superior, bem como as mudanças que as licenciaturas terão que realizar para atender essa nova demanda. Das conclusões, apontamos para a incongruência desta reforma quanto a melhoria no sistema escolar brasileiro, mostrando-se capaz de reduzir a variedade de conhecimentos a serem adquiridos pelos alunos, bem como suas possiblidades de inserção no mercado de trabalho em carreiras profissionais não tecnicistas.
\end{abstract}

Palavras-chaves: Reforma do Ensino Médio. Educação. Ensino Superior.

ABSTRACT: This study raises a brief reflection on the reform of secondary education decreed in 2017 by President Michel Temer and its relationship with higher education. Approved through a Provisional Measure (MP), this reform raised a series of controversies due to the lack of discussions with society about the changes that the reform would produce in the curriculum, such as the permission of the student to direct their studies according to with the area of greatest interest, and the possible approximation with the labor market. Moreover, the applicability of this reform by the Brazilian states still raises a lot of discussion, which justifies the relevance of the

\footnotetext{
${ }^{1}$ Professor de Educação Física (Faculdade Ratio) e Mestrando em Educação Física (Faculdade UNIGRENDAL). E-mail: heltonlima3103@gmail.com.

${ }^{2}$ Assistente Social e especialista em Saúde Pública (Universidade Estadual do Ceará - UECE). Email: emmanuella.martins@gmail.com.

${ }^{3}$ Assistente Social e especialista em Educação em Saúde (Universidade Estadual do Ceará - UECE). E-mail: chelampm@yahoo.com.br.
} 
reflection of the present study. Thus, the objective of this article is to analyze the effects that high school reform will have on training, access and presence of students from public schools in higher education, as well as the changes undergraduates will have to undertake in order to attend this new demand. From the conclusions, we point to the incongruity of this reform regarding the improvement in the Brazilian school system, showing itself capable of reducing the variety of knowledge to be acquired by the students, as well as their possibilities of insertion in the labor market into non-technical professional careers.

Key-words: High School Reform. Education. Higher education.

\section{INTRODUÇÃO}

"Não se faz reforma educacional por Medida Provisória." Daniel Cara, coordenador-geral da Campanha Nacional pelo Direito à Educação.

A frase acima, extraída de entrevista concedida à Revista Carta capital por Daniel Cara, nos auxilia em nosso questionamento em torno dos porquês da acelerada alteração da Lei de Diretrizes da Educação (LDB) a partir da Medida Provisória (MP) 746/2016 sancionada em fevereiro de 2017, passando a ser a lei no 13.415/2017, chamada de lei do Novo Ensino Médio. Questionada por desrespeitar a etapa do amplo debate, indispensável ao raciocínio prático e a credibilidade de qualquer modificação legal, teve como justificativa o baixo desempenho dos concludentes do ensino médio e a evasão escolar nessa última etapa da educação básica.

Sobre a questão, o filósofo e professor da Universidade de São Paulo (USP), Renato Janine Ribeiro, último Ministro da Educação no governo da ex-presidenta Dilma Rousseff, mencionou críticas sobre esta Medida Provisória (MP) e sua aplicação, pois com 120 dias de tramitação, esta não dilatou para a sociedade civil o debate preciso para pensar a referida reforma. Em entrevista à revista Correio Brasiliense, Renato aludiu ao fato de que o governo "inovou" ao se tratar de uma MP para marcar a alteração no currículo do ensino médio, inovação que vai na contramão do debate necessário a aprovação de uma lei desse porte. 
Renato ainda ressalta ser incomum o Congresso Nacional realizar um trabalho tão consagrado quanto o que foi efetivado na comissão do Ensino Médio. Se o processo continuasse e quando partisse para a votação em Plenário, o espaço de debate para a sociedade seria ampliado, podendo aprimorar o projeto estava sendo discutido desde 2012 e 2013. Desse modo, a MP mencionada trata de questão que estava sendo debatida na Câmara.

De acordo com o ex-ministro, o texto da MP não é um texto orgânico, pois modifica inúmeras leis voltadas à educação, o que exige mais debate sobre tema. Além disso, defendendo a ampliação da prioridade para uma gama de espaços a partir da oferta dos "eixos formativos", incumbe a escola a definição das áreas de afinidades, não ao jovem, já que ela será a responsável por recomendar quais eixos serão oferecidos, fundamentando-se nas situações econômicas e estruturais que a particularizam. Desse modo, a discussão não deveria girar em torno da dúvida se a reforma se concretiza, mas sim como se concretizará, pois já foi aprovada e concretizada, apesar dos inúmeros questionamentos realizados por pais, alunos, docentes e círculos especializados.

Outra questão que alimenta as críticas a MP aprovada no governo de Michel Temer, diz respeito as medidas tomadas, pois estão distantes do que a propaganda governamental divulgou. Nesta, veicularam-se imagens voltadas especificamente para o público jovem, sugerindo-se que este poderia escolher sua formação. Junto a isso, a suposta flexibilidade do novo currículo proposto para o ensino médio no Brasil desconsidera e desarticula todo o processo organizacional e de diretrizes da educação brasileira, que tem a Lei de Diretrizes e Bases da Educação (LDB) como seu principal eixo.

As mudanças citadas podem ser vistas especialmente na LDB. Pontuamos a alteração perpetrada ao caput do artigo 36 , que assim ficou:

O currículo do ensino médio será composto pela Base Nacional Comum Curricular ${ }^{4}$ e por trajetórias formativas, que necessitarão ser estabelecidos por intermédio da oferta de distintas disposições curriculares, de acordo com a proeminência para o contexto local e a probabilidade dos sistemas de ensino, a saber: I - linguagens e suas tecnologias; II - matemática e suas tecnologias; III - ciências da

\footnotetext{
${ }^{4}$ Documento de caráter normativo que define o conjunto orgânico e progressivo de aprendizagens essenciais que todos os alunos devem desenvolver ao longo das etapas e modalidades da Educação Básica.
} 
natureza e suas tecnologias; IV - ciências humanas e sociais aplicadas; V - formação técnica e profissional (BRASIL, 1996).

Essa categorização em áreas de conhecimento acentua outra crítica à reforma do ensino médio proposta na $\mathrm{MP}$, que é o seu caráter tecnicista, já que esquece das distintas características de cada saber e da interdisciplinaridade entre elas, observada por exemplo, na justaposição entre física ou química e filosofia ou história. Isso mostra a evidente conformação da MP com as demandas econômicas e de mercado, criando indivíduos sociais voltados para o trabalho e consumo, além de cidadãos afeiçoados à recente organização produtiva do capital.

A lógica incutida na reforma do ensino médio nos leva a pensar que, no longo prazo, ela impacte negativamente no ensino superior, pois os alunos ingressantes nesta etapa devem agregar conhecimento ao que os discentes construíram e partilharam na sua trajetória de vida, onde se inclui o ensino médio. Se o ensino médio não oferece o subsídio necessário ao processo de ensino e aprendizagem, mostrando-se fragmentado e diluído em um tecnicismo apto para responder as necessidades da ordem do capital, este processo se vê prejudicado.

Sabemos que num passado recente as políticas educacionais de viés compensatório se beneficiaram do acesso de inúmeras classes sociais ao nível superior. Assim, vários questionamentos surgem diante da materialização da reforma do ensino médio, tais como: Esta reforma implicará na má formação dos alunos, futuros profissionais, devido à fragmentação do conhecimento que esta propõe? $\mathrm{O}$ aluno que realizou o ensino médio numa escola que segue os preceitos desta reforma terá mais facilidade ou dificuldade de acessar o nível superior? Haverá distinção entre alunos oriundos de escolas públicas e os alunos oriundos de escolas privadas? As instituições de ensino superior exigirão competências adequadas às modificações propostas pela reforma do ensino médio? Com base nestas indagações, o objetivo geral deste texto é refletir sobre a reforma do ensino médio e seus impactos na formação de nível superior, a partir de pesquisa bibliográfica e documental.

\section{DESENVOLVIMENTO}




\subsection{REFORMA DO ENSINO MÉDIO: MAS, A FINAL, DO QUE SE TRATA E O QUE MUDA COM ELA?}

A reforma do ensino médio é uma alteração no mecanismo do sistema contemporâneo de ensino brasileiro. O governo garante que esta empreende uma melhoria na educação no país, pois oportuniza ao estudante escolherem a área de conhecimento que pretende aprofundar seus estudos, aproximando o ensino da realidade vivenciada pelo jovem que procura o mercado de trabalho (por meio de um curso profissionalizante). Dito de outro modo, o ensino médio é romantizado, uma vez que agora o jovem teria a oportunidade de concluir seus estudos, ao mesmo tempo em que já possuiria uma profissão necessária às demandas do mercado, abraçando sua vocação e seus sonhos de erguer uma vida profissional - com um posto de trabalho garantido.

O novo currículo proposto a partir da reforma do ensino médio será orientado pela Base Nacional Comum Curricular (BNCC), obrigatória para as instituições de ensino públicas e privadas, da educação infantil ao ensino médio. A BNCC determinará as competências e habilidades, a partir dos conhecimentos científicos fundamentais, que deverão ser oferecidas aos alunos na parte comum (1.800 horas), compreendendo as quatro áreas do conhecimento e os elementos curriculares presentes na LDB e nas diretrizes curriculares nacionais de educação básica.

A reforma em apreço se iniciou por meio da Medida Provisória $n^{\circ} 746 / 2016$, que:

Institui a Política de Fomento à Implementação de Escolas de Ensino Médio em Tempo Integral, altera a Lei $n^{\circ}$ 9.394, de 20 de dezembro de 1996, que estabelece as diretrizes e bases da educação nacional, e a Lei $n^{\circ} 11.494$ de 20 de junho 2007, que regulamenta o Fundo de Manutenção e Desenvolvimento da Educação Básica e de Valorização dos Profissionais da Educação, e dá outras providências. Medida Provisória $n^{\circ}$ 746, de 2016 (Reformulação Ensino Médio).

O texto final da Reforma do Ensino Médio foi publicado no Diário Oficial da União por meio da Lei no 13.415 que fez alterações na LDB, nos artigos 24, 26, 36, 44, 61, 62 e introduziu o artigo 35-A, modificando a prática e a eficácia de normas legais existentes que fortalecem a formação humana integral, o valor profissional do educador, assim como a autonomia pedagógica das escolas. Junto a isso, somente 
matemática, língua portuguesa e inglesa permaneceram obrigatórios em todo os anos do ensino médio, sendo consideradas disciplinas imprescindíveis nesta etapa de ensino básico.

O currículo ficará dividido em duas partes. Uma primeira será comum a todos os estudantes e uma segunda será dividida no que a referida lei intitula de "itinerários formativos" (art. 36, BRASIL, 2017), desdobrados em: 1) linguagens e suas tecnologias; 2) matemática e suas tecnologias; 3) ciências da natureza e suas tecnologias; 4) ciências humanas e sociais aplicadas; 5) formação técnica e profissional.

Cabe ressaltar neste primeiro momento que ao contrário do divulgado pelo governo, os itinerários formativos não serão necessariamente escolhidos pelo estudante. Na realidade, eles serão contemplados conforme as condições da escola em ofertá-los, o que depende de recursos e mão de obra qualificada. Isto significa dizer que a escolha dos itinerários formativos supramencionados, especialmente nas escolas públicas, pode se mostrar um engodo, uma ficção. Essa hipótese se sustenta no fato do déficit histórico e estrutural de recursos humanos em diversas áreas, o que mostra um possível cenário deficitário de mão de obra em muitas escolas de ensino médio. Por sua vez, para as escolas do ensino privado os itinerários formativos poderiam se configurar como novo nicho de mercado ou como bandeira de marketing, tendo em vista que estas últimas podem ofertar um maior leque de itinerários.

Outro aspecto desta reforma merece destaque: a proposta de "formação técnica e profissional", uma vez que fornece uma visão reducionista da dual escolha dentro do ensino médio, abrindo precedência para parcerias com o ensino privado, pagas com o recurso do Fundo de Manutenção e Desenvolvimento da Educação Básica e de Valorização dos Profissionais da Educação (FUNDEB). Também devemos assinalar que os itinerários formativos não irão exigir professores graduados, apenas sendo necessário comprovar seu "notório saber" (LDB, Art. 61, § IV) em qualquer habilidade técnica para receber o certificado para o exercício da docência.

Desta forma, acreditamos que a reforma do ensino médio terá repercussões na educação superior, desde a formação do magistério, em decorrência da Lei $n^{\circ}$ $13.415 / 2017$, pois esta retira a autonomia das universidades brasileiras no que dispõe o parágrafo $8^{\circ}$, do artigo 62 da LDB, que revela que "os currículos dos cursos 
de formação de docentes terão por referência a Base Nacional Comum Curricular" (BRASIL, 1996). A lei do Novo Ensino Médio almeja por sua vez fazer com que os docentes só possam "aprender a dar aulas" sobre o conteúdo que o Ministério da Educação (MEC) delibere.

A reforma do ensino médio, sendo voltada aos antigos moldes da modalidade profissional, atende apenas ao mercado de trabalho, em função dos rearranjos promovidos pelos grandes empresários, vinculados ao governo, apresentando uma ameaça às discussões sobre o sentido, as finalidades e os formatos que deveriam ter a última etapa da educação, o nível superior. Vale pensar, portanto, sobre a possibilidade da formação tecnicista transmitida ao jovem que acessará a universidade, carente do amadurecimento que o leve à compreensão crítica do trabalho e da sociedade.

Há uma demanda latente por um currículo mais prático, com matérias mais voltadas para a vida profissional, como economia, administração e relações financeiras, como se portar em uma entrevista, noções de ética e informações a respeito de informática e testes vocacionais. (NOGUEIRA FILHO, 2017, p. 1).

Entendemos que todo cidadão tem o direito de partilhar dos espaços e processos educativos. Porém, as políticas educacionais brasileiras parecem beneficiar o ingresso ao ensino superior sem os mesmos níveis de igualdade à diversidade dos estudantes. Observamos uma espécie de apartheid das classes sociais no ensino superior, pois o acesso às universidades públicas, consideradas como as responsáveis pelo melhor nível ensino, acaba ficando para os alunos oriundos das escolas privadas, enquanto os alunos advindos da escola pública terminam pagando pelo ensino superior privado. Assim, o déficit educacional do ensino médio público afasta o sonho de acessar o nível superior público e gratuito, podendo ser ampliado com a reforma do ensino médio.

A construção de uma sociedade que não reflete, sem conhecimento crítico e capacidade filosófica de questionar o presente, compreender o passado e projetar um futuro melhor se torna cada vez mais real. Neste cenário, o jovem, que pode ser um mero instrumento da "qualificação técnica" governamental/empresarial para o mercado de trabalho, também vê suas possibilidades de acesso ao ensino superior limitadas, quando sua formação na escola pública não lhe forneceu os conhecimentos necessários. 


\subsection{REFORMA NO ENSINO MÉDIO E SUAS IMPLICAÇÕES NO NÍVEL SUPERIOR: ALGUMAS CONSIDERAÇÕES}

A Medida Provisória (MP) no 746/2016, já em vigor sob a Lei no 13.415/2017 reestrutura o ensino médio de forma radical, trazendo em seu bojo implicações para toda a educação brasileira. A reforma do ensino médio redireciona a educação no Brasil não somente no que concerne aos aspectos teóricos, práticos e metodológicos, mas também às suas implicações diretas ou indiretas no ensino básico e superior.

Diante disso, urge questionar: A flexibilização dos conteúdos ensinados no ensino médio trará benefícios ou prejuízos à formação dos estudantes? O cenário atual onde a reforma do ensino médio se situa compromete a qualidade do ensino superior e o perfil dos futuros profissionais? A diferenciação entre educação pública e privada pode ser reafirmada com mais força em decorrência desta reforma? A lógica tecnicista-profissionalizante reforçará a hegemonia do capital, uma vez que o foco do ensino médio será voltado para o mercado de trabalho, sobrepondo-se à lógica acadêmico-científica?

O fato é que, apesar de nos últimos anos o debate sobre a temática da educação ter se intensificado em decorrência da participação de entidades científicas, movimentos sociais, gestores educacionais e parlamentares, entre outros sujeitos, esses e outros questionamentos ainda encontram-se em aberto, exigindo o desenvolvimento de posicionamento crítico e ações que garantam o melhor interesse do público envolvido.

Partimos do pressuposto de que o atual governo aprovou a reforma no ensino médio e tenta ludibriar a sociedade sobre sua eficácia, ancorado no discurso da necessidade de inovação e transformação que viriam atreladas aos valores positivos agregados à ideia de progresso e de melhoria do ensino médio. Contudo, esse discurso encobre uma dualidade no que concerne à oferta da educação: para os mais pauperizados, a escola elementar e a formação no ensino médio buscam preparar o jovem para um trabalho precarizado, enquanto que para os de classes mais abastados, a escola forma para empregos de maior qualidade, facilitando o acesso à universidade, muitas vezes, pública. Dito de outra forma: 
[...] em linhas gerais a reforma faz com que os estudantes sejam divididos entre aqueles que vão ter acesso a um ensino propedêutico e aqueles que vão ter acesso a um ensino técnico de baixa qualidade, trazendo à tona a educação como mercadoria, retirada do seu caráter de direito social (CARA, 2017, p. 4).

Sendo assim, cabe apontar a relação entre a reforma do ensino médio e o ensino superior, considerando os aspectos históricos, sociais, políticos, econômicos e culturais concernentes à realidade da sociedade contemporânea. Assim, devemos problematizar os inúmeros desafios presentes e as transformações enfrentadas pelo ensino superior, seja ele em instituições públicas ou privadas.

Um caminho para compreender o contexto de transformação do cenário educacional brasileiro é pontuar o que Ricci (2007) afirma, que mostra que desde a década de 1980 as reformas educacionais ocorrem um vários lugares do mundo, ligadas a fatores como a necessidade de formar profissionais mais qualificados para a operação de tecnologias sofisticadas quando inseridos no mercado de trabalho ocasionada pelo desenvolvimento econômico dos países.

O novo modelo do ensino médio prevê alterações de relevância na grade curricular e na carga horária; a implantação de reformas; a garantia de autonomia às escolas; a revisão de componentes socioculturais; o estímulo à formação profissional técnica, entre outras. Estas alterações trarão, segundo o MEC (2017), modificações significativas no acesso dos alunos ao ensino superior, uma vez que o próprio Exame Nacional do Ensino Médio (ENEM), hoje mecanismo de acesso às universidades públicas, também passará por readequações dentro da nova lógica de ensino.

Dentro desse contexto reformista, como pensar o ensino superior, instância final desse processo? A nosso ver, de um lado, temos a oferta de um ensino técnico profissionalizante e, de outro, um ensino voltado para o prosseguimento do "tão sonhado" ensino superior. Igualmente, cabe recordar que a suposta liberdade de escolha do jovem aluno sobre as instâncias formativas as quais pretende se aprofundar, pautada na autonomia e no projeto de vida de cada estudante, 
disfarçada de flexibilidade, remete, na verdade, a um verdadeiro empobrecimento e estreitamento curricular, que será impactado pela baixa qualidade do ensino.

Para Haddad (2007), é imprescindível a compreensão de alguns elementos pertinentes a esse processo, tais como: a incorporação de novos grupos sociais nas escolas e universidades; a falta de incentivo à carreira docente e aos programas de formação inicial ou continuada; a expansão do ensino superior e suas diversas modalidades; as questões de ordem social e econômica que interferem e adentram nas instituições educacionais; a injusta distribuição geográfica das instituições de ensino superior, uma vez que regiões economicamente mais desenvolvidas possuem uma maior concentração de instituições diante da escassez em regiões menos desenvolvidas.

Cabe dizer que o texto da reforma prioriza o eventual investimento no ensino médio, deixando de lado o ensino infantil, o que pode ser extremamente perigoso, pois no ensino infantil temos o início da vida estudantil. Logo, há necessidade de investimento neste nível de ensino para que os alunos possam ter condições de decidir o seu futuro profissional.

Sabemos que o acesso à educação nunca foi equitativo, em especial no ensino superior, já que as escolas públicas sofrem os prejuízos da falta ou insuficiência de recursos governamentais, afetando a qualidade do ensino gratuito, o que coloca o aluno de escola pública em desvantagem no acesso ao ensino superior. Em meio a esse cenário, o governo atende algumas reivindicações da sociedade civil com políticas compensatórias, que visam garantir o acesso à educação superior de qualidade por meio da expansão de instituições de ensino superior públicas, ou do financiamento de vagas em instituições de ensino superior privadas. No último caso, as políticas compensatórias acabam por materializar um processo de privatização da educação no Brasil, sustentado pelo discurso da competência do mercado e ineficiência do Estado (SILVA JÚNIOR, et al., 2011).

Percebemos, assim, a presença cada vez maior de estudantes oriundos da classe trabalhadora e das denominadas minorias na educação superior, como fruto dos mecanismos de inclusão através de políticas compensatórias. Isso traz à tona discussões sobre a política de igualdade social e a equidade de oportunidades educativas, bem como os programas de expansão do ensino superior, tais como: Programa Universidade para Todos (PROUNI), Financiamento ao Estudante do 
Ensino Superior (FIES), Reestruturação e Expansão das Universidades Federais (REUNI) e Universidade Aberta do Brasil $^{5}$ (UAB).

Devemos considerar, somando-se a estas evidências, a diversidade de grupos etários no ensino superior, diversificando os grupos estudantis e a estrutura curricular dos cursos, o que ajuda a promover um processo paulatino de diferenciação no processo de ensino e aprendizagem. Vale dizer, por isso, que é notório o progresso obtido na educação superior brasileira no período de 2003 a 2014, apesar dos desafios, contradições e dificuldades.

A verdade é que a educação superior brasileira está envolta numa política educacional marcada por jogos de interesses, configurando-se como um campo em disputa. As visões sobre esta realidade vão desde um possível projeto de desenvolvimento nacional, quando visto do ponto de vista governamental, a um meio de ascensão social e possibilidade de democratização de direitos, até os interesses de mercado, quando analisado do ponto de vista empresarial (MANCEBO, 2004).

Compreender essa gama de elementos e interesses diversos que permeiam a educação no Brasil aponta para a certeza de que o debate sobre a reforma do ensino médio e sua relação com o ensino superior apenas foi lançado, necessitando assim pensar a educação em todos os seus níveis de ensino, pois o ensino fundamental e o médio são importantíssimos para o acesso ao ensino superior.

\section{CONSIDERAÇÕES FINAIS}

Falar sobre o ensino brasileiro e, de modo particular, sobre a reforma do ensino médio, é de suma relevância e pode contribuir para a ampliação do debate a respeito destes elementos. Compreendemos, assim, ao longo deste texto, que a reforma do ensino médio, implementada pelo atual governo federal, está aquém do necessário para a realização de melhorias no sistema escolar brasileiro, tratando-se, portanto, de uma reforma dispensável, que prejudica mais do que auxilia os alunos, principalmente nas suas possibilidades de escolha de carreiras futuras, onde se

\footnotetext{
${ }^{5}$ A UAB trata da educação superior a distância com a criação de vários polos em todo país, inclusive em regiões desprivilegiadas.
} 
encontra o acesso ao ensino superior.

Não obstante ao fato de esta reforma haver sido aprovada sem o mínimo de debate, fugindo da política que deveria ser aplicada por um estado democrático de direito, como é o Brasil, esta reflete também nas condições e visões de um governo que tem se mostrado capaz de não considerar, através do debate público, as opiniões da sociedade.

Devemos ressaltar que é incoerente a aprovação de uma reforma educacional tão importante por meio de uma medida provisória, como ocorreu com a MP 764/2016. A Constituição Federal de 1988, por intermédio do seu artigo 206, inciso sétimo, prevê, inclusive, a gestão democrática do ensino público, o que não foi possível tendo em vista a celeridade governamental em implementar a referida mudança (BRASIL, 1988). Além disso, no que diz respeito à prática efetiva do dia a dia dos alunos, a reforma em apreço os dividirá entre os que terão um ensino de qualidade e os que terão ao seu dispor um ensino insuficiente para "competir" em igualdade com candidatos advindos de escolas de melhor ensino, refletindo diretamente no acesso ao ensino superior.

Como apresentado, com a reforma do ensino médio o currículo será dividido entre conteúdo comum e específicos escolhidos pelo estudante, por exemplo, linguagens, matemática, ciências da natureza, ciências humanas e formação técnica. Com esta reforma, temos, portanto, um retrocesso lamentável para a educação no Brasil. Esta contribui para a ampliação do fosso existente entre ricos e pobres, principalmente em relação à oportunidade de desenvolvimento intelectual e acesso à educação superior.

Desse modo, o cenário educacional brasileiro oportuniza às escolas da rede privada mais opções de itinerários formativos, oferecendo-Ihes maior possibilidade de acesso ao ensino superior (público ou privado) e às profissões de maior ascensão, enquanto que aos alunos das escolas públicas sobram-lhes uma formação tecnicista e voltada para a profissionalização para o mercado. Isto nos permite concluir que a reforma do ensino médio é incoerente, pois não melhora o sistema escolar brasileiro, mas reduz as possiblidades de inserção equitativa no mercado de trabalho em carreiras profissionais não tecnicistas e de bons salários aos estudantes oriundos de escolas públicas organizadas segundos os parâmetros desta reforma. 


\section{REFERÊNCIAS}

BRASIL. Medida Provisória n. 746, de 22 de setembro de 2016. Institui a Política de Fomento à Implementação de Escolas de Ensino Médio em Tempo Integral. Disponível em: <http://www.planalto.gov.br/ccivil 03/ ato20152018/2016/Mpv/mpv746.htm. . . Acesso em: 04.jan.2018.

BRASIL. Ministério da Educação. Novo Ensino Médio. 2017. Disponível em: <http://portal.mec.gov.br/publicacoes-para-professores/30000-uncategorised/40361-novoensino-medio-duvidas>. Acesso em: 04.jan.2018.

BRASIL. Constituição (1988). Constituição da República Federativa do Brasil. Brasília: Senado, 1988.

CARA, Daniel. Reforma do Ensino Médio é um retorno piorado à década de 90. 2017. Disponível em: <http://www.vermelho.org.br/noticia/293098-1>. Acesso em: 04.jan.2018.

CASTRO, C. de M. Educação Brasileira: consertos e remendos. Rio de Janeiro: Rocco, 2007.

CORREIO BRASILIENSE. Renato Janine, critica a elaboração da reforma do ensino médio via MP. Disponível em: $<$ https://www.correiobraziliense.com.br/app/noticia/brasil/2016/09/24/interna-

brasil,550271/renato-janine-critica-a-elaboracao-da-reforma-do-ensino-medio-via-mp.shtml> Acesso em: 20 de dezembro de 2018.

HADDAD, Fernando. Plano de Desenvolvimento da Educação - PDE. Brasília: Ministério da Educação, 2007.

MANCEBO, Deise. Universidade para todos: a privatização em questão. Pro-Posições, v. 15, n. 3, p. 75-90 set./dez. 2004.

MEC. LDB - Lei no 9394/96, de 20 de dezembro de 1996. Estabelece as diretrizes e bases da Educação Nacional. Brasília: MEC, 1996.

NOGUEIRA FILHO, Olavo. Gerente geral do TPE, fala no quadro De Olho na Educação sobre os desafios dos novos prefeitos na área educacional. 2017. Disponível em: http://educacao.estadao.com.br/blogs/de-olho-na-educacao/nao-podemos-isolar-adiscussao-sobre-qualidade-da-demanda-por-abertura-de-vagas/>. Acesso em: 02.jan.2018.

SILVA JÚNIOR, João dos Reis da.; LUCENA, Carlos; FERREIRA, Luciana Rodrigues. As relações entre o ensino médio e a educação superior no Brasil: Profissionalização e Privatização. Educ. Soc., Campinas, v. 32, n. 116, p. 839-856, jul./set. 2011. Disponível em: $<$ http://www.cedes.unicamp.br>. Acesso em: 29.dez.2017. 